\title{
EDUCAÇÃO DO CAMPO E ABORDAGEM CIÊNCIA, TECNOLOGIA E SOCIEDADE: UM DIÁLOGO POSSÍVEL
}

\section{RURAL EDUCATION AND SCIENCE, TECHNOLOGY AND SOCIETY APPROACH: A POSSIBLE DIALOGUE}

\author{
Maria José Aguiar dos Reis Silva ${ }^{1}$ \\ Marcelo Ximenes Aguiar Bizerril ${ }^{2}$
}

\begin{abstract}
Resumo: A Educação do Campo perpassou uma trajetória de conquistas e efetivação de direitos. Consequentemente, as produções acadêmicas cresceram efetivamente, todavia, o Ensino de Ciências ainda não está presente em boa parte do que se produz. A proposta de sociedade, a visão de mundo e o projeto de país da Educação do Campo são a base para uma nova perspectiva a respeito da ciência que se propõe para/do e no campo. A abordagem da Ciência, Tecnologia e Sociedade - CTS para o Ensino de Ciências, apresenta-se como uma abordagem que favorece a constituição da área do Ensino de Ciências. O objetivo do texto, à luz das bases teóricas, é a promoção do letramento científico e a formação cidadã em que os estudantes possam compreender a realidade e a vida como um conjunto de fatores biológicos, químicos e físicos, compreendendo a Ciência como um meio de interpretar a vida.
\end{abstract}

Palavra-chave: Educação do Campo; ensino de ciências; abordagem CTS.

\begin{abstract}
The Rural Education went through a trajectory of achievements and enforcement of rights. Consequently, academic productions have effectively grown, however, Science Teaching is not yet present in much of what is produced. The proposal of society, the world view and the country project of Rural Education are the basis for a new perspective on the science that is proposed to/from and in the rural area. The approach of Science, Technology and Society - CTS for Science Teaching, is presented as an approach that favors the constitution of the area of Science Teaching. The aim of the paper, in the light of theoretical bases, is the promotion of scientific literacy and citizen formation in which students can understand reality and life as a set of biological, chemical and physical factors, understanding science as a means of interpreting life.
\end{abstract}

Keyword: Rural Education; science teaching; CTS approach.

\section{Introdução}

As propostas da Educação do Campo para a sociedade brasileira, estão na direção de fortalecer o campo, não só como um lugar de produção de bens materiais, todavia de produção e reprodução da vida, onde se constrói saberes, no sentido de tornar ainda mais democrático o acesso ao conhecimento de forma menos propedêutica e fragmentada aos camponeses, que já convivem com o histórico de reprodução de um ensino urbano inaplicável à dinâmica e à realidade do campo.

O Ensino de Ciências nas escolas do campo ainda é um tema pouco explorado, portanto muito incipiente. A superação entre a distância da teoria e da prática é além de uma necessidade, um ideal da Educação do Campo. Superar a visão simplista e ingênua como a ciência foi apresentada aos estudantes através de um modelo tradicional de ensino, pautada num modelo ideológico de educação dominadora e subordinante.

\footnotetext{
${ }^{1}$ Secretaria de Estado da Educação de Goiás, Planaltina, GO, Brasil.

${ }^{2}$ Universidade de Brasília, Brasília, DF, Brasil.
} 
A consideração das especificidades da Educação do Campo ainda é recente em nosso meio, sendo por muitos desconhecidas e desconsideradas. Assim, poucas mudanças foram observadas para o ensino de Ciências das escolas do campo e vislumbramos uma longa trajetória para que ocorra a implementação de fato da Educação do Campo. (KLIEMAN 2017).

A produção do conhecimento na Educação do Campo vem ao longo do tempo se fortalecendo através dos trabalhos de pesquisadores e egressos das diversas licenciaturas em Educação do Campo que ingressaram em programas de pós graduação espalhadas pelo país. Mesmo assim, é possível perceber que o Ensino de Ciências especificamente recebeu poucas produções. Analisando uma pesquisa realizada com o objetivo de avaliar o histórico dessas produções (MOLINA et al., 2019), tem-se clareza a respeito das produções no banco de teses e dissertações ao longo de nove anos, e a riqueza das mesmas, todavia observa-se que pouco menos de dez por cento dentre elas são relacionadas ao Ensino de Ciências.

Diante dessa realidade, o presente trabalho se propõe a estabelecer um diálogo entre a Educação do Campo e a abordagem da Ciência, Tecnologia e Sociedade. Essa a abordagem para o Ensino de Ciências também pode se configurar como uma contribuição na constituição à área de Ciências da Educação do Campo. A abordagem CTS, tal como apontada por Santos e Mortimer (2002), tem um caráter relacional, que evidencia as diferentes dimensões do conhecimento, as interações entre Ciência, Tecnologia e Sociedade, é imprescindível à construção de um pensamento crítico do desenvolvimento científico, das aplicações tecnológicas e seu impacto social.

Sua natureza essencialmente voltada à formação cidadã é uma resposta aos rumos de uma Ciência voltada apenas para formação de cientistas, no modelo de mundo capitalista, consumista, sem preocupações com os impactos ambientais do desenvolvimento da tecnologia, que distanciava as possibilidades de acesso ao conhecimento à sociedade consequentemente impossibilitaria a compreensão, o debate e influência nas decisões.

\section{Educação do Campo}

A concepção de Educação do Campo se constitui historicamente. Nesse sentido as contribuições e esclarecimentos (CALDART, 2012) para se pensar nesta proposta de educação que está inteiramente ligada à proposta de sociedade. São as ideias da autora que norteiam esta parte da pesquisa relacionada à temática Educação do Campo, passando desde o panorama histórico até concepções epistemológicas. Em princípio ela aponta a tríade estruturante: campo, políticas públicas e educação diretamente relacionadas ao conceito central, a partir daí discorrendo sobre os demais aspectos deste conceito em construção.

As dimensões pedagógicas da educação do campo, com suas raízes no campo, no projeto de campo, na educação popular e intrinsecamente relacionada à dinâmica dos movimentos sociais do campo, retoma matrizes da educação. Estas matrizes são a emancipação, a libertação, a humanização e a formação do sujeitos. (BARBOSA, 2012).

Em um breve histórico (CALDART, 2012) da Educação do Campo de forma sucinta, informa que: em 1997 ocorreu o Primeiro Encontro Nacional dos Educadores e Educadoras da Reforma Agrária (I Enera) realizado pelo MST, a partir do qual foi então proposto um desafio para discussão mais ampla sobre educação no meio rural brasileiro, e então em 1998, ocorre a I Conferência Nacional por uma Educação Básica do Campo - 1998, e em 2002 realiza-se o I Seminário Nacional de Educação do Campo, suprimindo-se a palavra Básica, em função da compreensão do direito também à educação superior, portanto ampliando-se o leque das lutas pelo direito à educação do campesinato. 
A autora usa como argumentos para o contraponto de forma e conteúdo à denominada Educação rural, o sentido atual do trabalho camponês; das lutas sociais e culturais dos grupos que tentam garantir a sobrevivência deste trabalho; educação que se volta ao conjunto dos trabalhadores e trabalhadoras do campo, quilombolas, nações indígenas, assalariados vinculados à vida e ao trabalho rural e resgate ao conceito de camponês, histórico e político.

O parecer do Conselho Nacional da Educação - CNE (BRASIL, 2002) no 36/2001 que normatiza as Diretrizes Operacionais para Educação Básica nas Escolas do Campo, estabelece que "a educação compreende todos os processos sociais de formação das pessoas como sujeitos do seu próprio destino." E ainda que "educação tem relação com cultura, com valores, com jeito de produzir, com formação para o trabalho e para participação social."

A necessária transformação educacional para os camponeses foi protagonizada pelo Movimento dos Trabalhadores Sem Terra, mas depois houve necessidade de alcançar um cenário mais amplo compreendendo todos os trabalhadores do campo. A Educação do Campo como prática social está em processo de constituição histórica, e tem algumas características principais que expressam sua consciência de mudança (CALDART, 2012). São algumas destas características: a) luta social pelo acesso aos trabalhadores do campo à educação, com sujeitos protagonistas deste processo (não é para nem com, mas dos camponeses - expressão da pedagogia do oprimido); b) dimensão de pressão coletiva por políticas públicas mais abrangentes (também em cada local ou situação particular dos grupos sociais que a compõe); c) combina luta pela educação com luta pela terra, Reforma Agrária, direito ao trabalho, a cultura, à soberania alimentar, ao território. d) defende a especificidade das lutas e das práticas por ela geradas, mas não em caráter particularista; e) práticas que reconhecem e buscam trabalhar com a riqueza social e humana da diversidade de seus sujeitos, com vistas à superação das relações capitalistas no campo e na cidade; f) não nasceu como teoria educacional pois trata de prática e de lutas contra hegemônicas, exige teoria, rigor de análise da realidade concreta, perspectiva da práxis; g) de forma mais ampla, se interessa pela totalidade apesar do direito de pensar a pedagogia em sua realidade específica; h) escola é o objeto central de lutas e reflexões pedagógicas; i) busca a luta pelo acesso à educação pública com a luta contra a tutela política e pedagógica do Estado (não deve ser o Estado o educador do povo); j) educadores são sujeitos fundamentais da formulação pedagógica e das transformações da escola.

A Escola do Campo se dá no enfrentamento da ciência constituída nos moldes do capitalismo, avançando contra a neutralidade do conhecimento científico construído pela humanidade, ela deve estabelecer um diálogo com a realidade dos camponeses tentando propor soluções para os problemas cotidianos que tentam superar a lógica do sistema capitalista (MOLINA; SÁ, 2012a).

Por outro lado e no mesmo sentido, encontra-se o Ensino de Ciências que se propõe a desmistificar a Ciência, como um bem que só um seleto grupo pode possuir ou obter, servindo para a dominação e alheia às discussões sociais. $\mathrm{O}$ ensino de ciências que possa proporcionar ao cidadão condições de participar das discussões que o afetam diretamente, do desenvolvimento de tecnologias que facilitam a vida diária, ou até mesmo que torne o indivíduo capaz de compreender a vida em sua totalidade.

A Educação do Campo comunica sua concepção pedagógica com este Ensino de Ciências ao propor que seus sujeitos possam de forma emancipatória compreender a relação e o processo de construção de conhecimento científico atrelado às questões econômicas, políticas e culturais. Assim acontece com a história do conhecimento científico, ele é construído por coletivos, pares, homens, mulheres que influenciados por fatores econômicos, culturais e políticos se constituem. A ciência não é neutra, não há um só método de fazê-la, também não visa 
desacreditar o senso comum, todavia, superar a ingenuidade do conhecimento e reconhecer que há outros conhecimentos e formas de construção de saberes.

O olhar que lançado sobre o ensino de Ciências nas unidades escolares do meio rurais, o processo de ensino aprendizagem é quase que exclusivamente baseado no livro didático (ARAÚJO E CARDOSO, 2009). Para as autoras, o currículo escolar de Ciências sempre foi pautado pela Ciência ocidental moderna para priorização e seleção dos saberes para instrumentalizar. Por isso, quando a ênfase está no sistema dominante, a cultura popular é depreciada. As ciências que se ensina, ainda segundo as autoras, é aquela Ciência neutra sem relação social e ética, fazendo uso de modelos da realidade que são considerados corretos e inquestionáveis.

Deste modo, é uma máxima da Educação do Campo, que os conhecimentos e os saberes produzidos pelos camponeses sejam ponto de partida para se construir novos conhecimentos. Neste sentido, a escola deve exercer sua potencialidade na formação de sujeitos autônomos, compreendendo que a escola do campo tem um caráter muito mais amplo do que se costuma explicitar a respeito do modelo do sistema vigente.

A escola do campo em sua tríade estruturante escola-campo-políticas públicas oferece ao educando a possibilidade de compreensão da sua realidade a partir de um olhar em que se atrelam os conceitos principais da luta dos povos do campo. É imprescindível que a relação da luta pela terra, e a efetivação de políticas públicas como direito a educação no e do campo, sejam fontes geradoras de questões para problematização, e compreensão da natureza e objeto das ciências.

No entendimento da Educação do Campo, trazer a vida como princípio, nos aponta para uma educação que parte da realidade, educação onde os sujeitos estão em um contexto social, político, cultural e econômico. A escola está inserida também nesta realidade e por isto, a educação que se propõe a através dela deve partir da vida num processo integral.

A escola do campo tem uma identidade que a vincula à realidade:

Parágrafo único. A identidade da escola do campo é definida pela sua vinculação às questões inerentes à sua realidade, ancorando-se na temporalidade e saberes próprios dos estudantes, na memória coletiva que sinaliza futuros, na rede de ciência e tecnologia disponível na sociedade e nos movimentos sociais em defesa de projetos que associem as soluções exigidas por essas questões à qualidade social da vida coletiva no país. (BRASIL, 2002)

O Ensino de Ciências no modelo vigente não atende à demanda da Educação do Campo em trazer o conhecimento escolar para a vida, de maneira a tornar-se participante e não meramente um receptor de conhecimentos desconexos da realidade. Há alguns enfoques e abordagens para o ensino de ciências nas escolas do campo que contribuem no sentido de superação da fragmentação do conhecimento e da inserção da realidade material da vida dos estudantes.

O esforço coletivo em promover o Ensino de Ciências no curso de Licenciatura em Educação do Campo que seja por organizado por área, tem sido buscando por diferentes coletivos de educadores que, para isso, realizam reuniões periódicas de planejamento com o grupo de professores acompanhando e avaliando as atividades desenvolvidas (BRITO e SILVA, 2011). No entendimento das autoras, só assim será possível elaborar coletivamente novas práticas e superar a maneira fragmentada, desvinculada da realidade em que os conteúdos de Ciências são trabalhados e ensinados. Essas mesmas autoras fazem uma crítica à maneira como os conteúdos de Ciências estão organizados nas diferentes séries. Para elas, são quatro blocos que tratam necessariamente a respeito do corpo humano; os seres vivos e alguns aspectos superficiais; trabalham os seres não vivos e por último o meio ambiente e pontualmente a poluição. Há um grande problema neste modelo, as autoras esclarecem que será de maneira muito incipiente a contribuição da escola em formar visando a melhoria na qualidade de vida 
das pessoas. Para elas, o exercício do diálogo coletivo irá suscitar em uma complexificação a respeito do modelo em que se organizam os conteúdos.

Ainda apontam alguns critérios a serem considerados na organização curricular: hierarquização dos saberes e das áreas disciplinares; dificuldades na realização de um planejamento coletivo; os sujeitos e as limitações da formação; o compromisso profissional de uns em detrimento do descompromisso de outros. Eles certamente influenciaram significativamente nos conhecimentos, recursos e estratégias para promover a superação da fragmentação e articulação destes com a realidade.

É imprescindível que o coletivo de professores da área de Ciências, envolvidos com a formação inicial ou continuada da Educação do Campo, una-se no esforço tanto de pensar novas estratégias de formação por área do conhecimento quanto de socializá-la. Complementam ainda, que o "desafio atual do currículo de Ciências é tratar uma gama de conhecimentos a partir de suas dimensões mais amplas como formação histórica e epistemológica" (LIMA, 2010 apud BRITO e SILVA, 2011).

\section{O ensino de ciências e abordagem da Ciência, Tecnologia e Sociedade - CTS}

O Ensino de Ciências no Brasil avançou de forma significativa nas últimas décadas, com um novo paradigma que se apresenta para superar o paradigma moderno de supremacia do conhecimento científico sem compromisso social, histórico, ético, econômico e político. Nesse sentido, "não há como ensinar Ciências utilizando o conceito de forma pura e neutra, sem relacioná-la ao contexto social, pois os estudantes e os professores de uma escola são seres sociais que crescem e se desenvolvem na e com a sociedade." (KLIEMANN, 2017).

O texto de Mortimer (2010), ao abordar questão do ensino de ciências e a vida, faz uma comparação entre a chama de uma vela e o cristal, referindo-se à vida do estudante e ao conhecimento científico proporcionado pelo ensino de ciências respectivamente. Nos remete à uma realidade muitas vezes ignorada no cotidiano escolar, nas formas de abordagem da ciência e na avaliação de ensino - aprendizagem. $\mathrm{O}$ autor aponta que o estudante não tem o dever de aceitar uma nova visão de mundo totalmente diferente da sua, essa nova visão na maioria das vezes é fria, sem dinamismo e os sujeitos geralmente não existem, comparando ao cristal.

Para Fourez (1995) é imprescindível capacitar o cidadão para participar das discussões, compreender o que dizem os especialistas, além de agir e tomar decisão. $\mathrm{O}$ Ensino de Ciências com estas perspectivas estão presentes, tanto nos pressupostos da Educação do Campo, quanto na abordagem CTS.

Cabe destacar que a abordagem CTS, emerge de dentro de um cenário sócio econômico da Ciência e Tecnologia que gerou problemas ambientais e destes problemas surgiu a necessidade de uma mudança sobre a natureza da ciência e do seu papel na sociedade. Fato que evocou uma perspectiva para educação em ciências com vistas a formação para cidadania (SANTOS, 2011).

O mesmo autor, aponta que na educação científica, "o movimento CTS assumiu como objetivo o desenvolvimento da capacidade de tomada de decisão na sociedade científica e tecnológica e o desenvolvimento de valores (SANTOS, 201, p. 23). Isto contribuiu no sentido de estar presente questões que apontam para a cidadania, ética e questões ambientais.

Santos (2011) constatou que nos anos de 1980 e 1990 projetos curriculares de Ciências com perspectiva CTS contribuíram para o seu fortalecimento, posteriormente o desenvolvimento de pesquisas até sua constituição em linha de pesquisa do Ensino de Ciências. A partir do ano 2000 foi percebido redução nas publicações com o tema CTS refletindo a perda de forças, fato que se deve também às diferentes nomenclaturas posteriormente utilizadas. Apesar destas constatações, o movimento não está inativo e se expande de forma significativa. 
Santos e Mortimer (2001) fazem uma análise dos pressupostos CTS para educação brasileira, afirmando que os currículos construídos com este enfoque são viáveis ao momento atual, especialmente por contribuir para alfabetização e o letramento científico e tecnológico. Apontam ainda que a realidade onde as propostas curriculares em CTS foram desenvolvidas são outras diferentes da brasileira e requerem uma adequação crítica.

Os estudantes necessitam de uma formação mais coerente com sua realidade, e o Ensino de Ciências que atue também como lentes para compreender o mundo. Há uma preocupação quanto aos currículos de ciências pobres de assuntos sociais, o que prejudica a formação integral dos estudantes. Um currículo com abordagem CTS deve superar a matriz dos temas transversais para auxiliar o trabalho disciplinar, mas deve aparecer como uma abordagem do Ensino de Ciências, entendendo também que o estudante deve olhar criticamente para os avanços tecnológicos, seus impactos sociais e em qual contexto eles se constrói (SANTOS; MORTIMER, 2001)

Citando Roberts (1991, apud Santos; mortimer, 2001, p. 3) os currículos de ciências devem ter as inter-relações com a explicação científica, o planejamento técnico e solução de problemas, além da tomada de decisão. Assim, seremos capazes de formar cidadãos críticos, com condições de atuar na sua realidade, com bases teóricas como ferramenta do diálogo e para sua visão de mundo.

Temos então, na abordagem CTS uma resposta à necessária mudança no ensino de ciências, pois esta abordagem tem "como principal meta preparar os alunos para o exercício da cidadania”. (SANTOS; MORTIMER, 2001).

É imprescindível na perspectiva da educação emancipatória da Educação do Campo, que o estudante seja sujeito no seu processo de construção do conhecimento. Além dessa intencionalidade, é possível compreender a relação da abordagem CTS e a Educação do Campo quando os sujeitos do campo acessando os conhecimentos científicos possam compreender suas inter relações, as questões econômicas, sociais, políticos, culturais e ambientais nos quais estão inseridos. Além disto situarem-se num contexto maior, global é premissa emergente das concepções de ensino e propostas metodológicas para a educação dos camponeses.

Daí internalizar que entender a natureza da ciência é fundamental para entender as implicações sociais. Pois "a ciência e a tecnologia têm interferido no ambiente e suas aplicações têm sido objeto de muitos debates éticos, o que torna inconcebível a ideia de uma ciência pela ciência, sem consideração de seus efeitos e aplicações" (SANTOS, 2002).

A não exploração das dimensões sociais no ensino de ciências é alimentar os interesses sociais e econômicos, o sistema vigente regido pelo capitalismo e seus sujeitos. Ainda neste contexto, o valor de um ensino pela abordagem CTS é essencial para a formação de sujeitos com potencial para ter habilidades, atitudes, cidadania crítica e conhecimento das relações entre o conhecimento aprendido e a vida. (SANTOS; MORTIMER, 2001)

O panorama da dupla faceta da abordagem CTS que estão intrinsecamente relacionadas a Ciência e a Tecnologia, nos esclarece que num movimento de Educação do Campo que busca uma contra hegemonia e está imersa na realidade do desenvolvimento tecnológico, como conceito em construção deve ter clareza destas concepções.

Para Fourez (1995) o entendimento sobre a natureza da ciência dá-se quando é possível compreender em suma, que ela possui um método, sua observação não é passiva, os fatos são modelos teóricos não neutros, há uma construção social da realidade. Enfim, é preciso que se valorize o aspecto da ciência enquanto construto humano, retirando cada vez mais a visão absolutista da ciência.

Diferentes pessoas usam o termo tecnologia em diferentes situações e contextos, todavia, ainda por isso é comprovado não haver um conteúdo inequívoco para defini-la. Mas o autor afirma ser imprescindível a clareza a respeito da tecnologia e da técnica. Ainda apresenta um forte argumento para que se possa compreender a ideologia que é o pano de fundo das 
concepções de tecnologia. Seu discurso nos ajuda a ter um panorama muito amplo sobre a tecnologia e suas implicações sociais (PINTO, 2005)

Para uma construção curricular com ênfase CTS, a clareza do contexto e as representações conceituais de cada um dos aspectos desta trilogia norteará o significado da educação que se pretende e assim não tornará o currículo uma tentativa frustrada de educação CTS. Para isto, toma-se por base o que dizem Santos e Mortimer (2002) a respeito das leituras realizadas. Nos clarificam sobre a Ciência presente nos currículos CTS, quando afirmam que ela tem uma dimensão mais ampla, avançando para além da investigação científica e significado de conceitos. Ciência esta que não é um ensino do cotidiano, enciclopédico que não contempla as relações com os problemas sociais.

Para os autores, Tecnologia é vista como o conhecimento que possibilita o controle e a modificação do mundo. Diferente do que acredita atualmente a ciência aplicada, Vargas (1994 apud SANTOS; MORTIMER, 2002) diz que a tecnologia é um conjunto de atividades humanas, associada à cultura num conhecimento sistematizado, construção de obras e fabricação de produtos. Quando a tecnologia é vista por meio de seus aspectos culturais e organizacionais, é possível compreender sua dependência do contexto sócio político, dos valores e das ideologias culturais. Para superar a alienação e libertar os sujeitos visando um desenvolvimento sustentável é preciso mais que saber manusear, entender seu funcionamento e estar preparado para aprender mais. Para Vieira Pinto (2005) "o domínio teórico da técnica pelo homem liberta-o da servidão prática à técnica, que vem sendo, crescentemente, o modo atual de vida pelo qual é definido e reconhecido" (p. 223).

Os temas científicos são indissociáveis da Sociedade e seus problemas, todos estes devem partir de uma contradição com possibilidades de serem confrontados por diferentes pontos de vista. Trata-se também do desenvolvimento da cidadania, da ética e valores humanos (Santos; mortimer, 2002). Citando Ransey (1993 apud Santos; mortimer, 2002) há critérios para que um tema seja considerado tema social relativo à Ciência, em suma deve ser e ter problema de natureza controvertida; significado social e relativo a Ciência e a Tecnologia.

Esse entendimento não tem a intencionalidade de explorar em separado a Ciência, a Tecnologia e a Sociedade, pois a abordagem que se defende neste trabalho é justamente a inteira relação de ambos e não sua fragmentação.

A tecnologia puramente pela técnica retira da discussão o humano, o trabalhador que domina a técnica. Por isso, Dusek (2009) aponta também definições de tecnologia, todavia afirma que nenhuma definição geral é possível. Neste entendimento é possível concluir que definir tecnologia sem desbravar horizontes que não estão explícitos em conceitos é assumir uma ideologia.

Deste modo, quando encontramos um ponto de diálogo com a abordagem CTS, na perspectiva de "recuperar o vínculo com a formação humana e a produção material da existência"(CALDART, 2012, p. 265) na Educação do Campo, pensando estes vínculos a partir da realidade específica, em destaque a agricultura camponesa, a agroecologia, a desigualdade social, vida humana e terra, produção de alimentos saudáveis, relações de respeito à natureza, ciência, tecnologia, cultura (CALDART, 2012).

\section{Considerações finais}

Sobre tudo que temos discorrido neste texto, cabe destacar algumas questões que até o presente momento são relevantes para o diálogo entre a Educação do Campo e a abordagem CTS. Primeiro, a Educação do Campo assim como a abordagem CTS tem sua origem numa realidade de descontentamento a respeito dos rumos tanto da educação como da ciência respectivamente. Por 
conseguinte, a Educação do Campo tem como premissa a formação integral dos sujeitos, no sentido da contextualização, autonomia, formação de valores, protagonismo e visão de mundo;

Portanto, a Educação do Campo pode se fortalecer não só pelas vias do embate ideológico, todavia com vistas a procurar caminhos para uma educação que visa não só a contra hegemonia da tecnologia, mas se valer de seus princípios para buscar de uma sociedade mais igualitária e equânime. É imprescindível a introdução de outros referenciais teóricos que contemplem a ciência como construção humana, imersa numa realidade cultural, histórica, econômica e política. A ciência pode dar condições ao cidadão de fazer uma leitura de mundo, refletir sobre a realidade, capacitar para tomada de decisão e participar ativamente das discussões do desenvolvimento científico e tecnológico que o afetam diretamente.

Aikenhead (2009) sinalizou que o currículo CTS reflete os objetivos de formação que se pretende, e em outro trabalho apresenta um quadro que evidencia as diferenças entre as categorias e os objetivos gerais de CTS (AIKENHEAD, 1994 apud SANTOS; MORTIMER, 2002). Para ele, este quadro pode auxiliar quais tipos de objetivos do enfoque CTS podem estar presentes no currículo. Acredita-se também que seria uma ferramenta para se ter clareza da ampla abordagem desse enfoque e suas contribuições na formação cidadã.

Esta abordagem tem uma melhor aplicabilidade na realidade brasileira por meio dos pressupostos da abordagem temática de Freire (FREIRE, 1987) e na sua releitura encontrada em Delizoicov et al. (2009), e nos trabalhos de Watanabe (2009) e Strieder (2009).

As práticas de cada professor devem ser pautadas nos pressupostos CTS para que essa proposta possa ter sentido, não basta ter um currículo reconfigurado sem haver reflexões teóricas e epistemológicas. O enfoque CTS não é suficiente para resolver todos os problemas de uma educação tradicional e marcada pela memorização de fórmulas e conceitos vazios, para que haja realmente uma transformação é necessária uma mudança conceitual.

As bases teóricas (FREIRE, 1987, DELIZOICOV et al. 2009, STRIEDER, 2008, WATANABE, 2009, CALDART, 2011) destes conceitos de CTS para o Campo apontam para o objetivo de promover uma alfabetização científica e formação cidadã onde os estudantes possam compreender sua realidade e a vida como um conjunto de fatores biológicos, químicos e físicos, compreender a Ciência como um meio de interpretar a vida, o desenvolvimento da tecnologia seus processos e impactos sociais, capacitando o indivíduo para o exercício da cidadania.

Considera-se que o percurso para estabelecer fundamentos teóricos para um efetivo Ensino de Ciências que se vislumbra na sociedade atual e na Educação do Campo está sendo construído. É inegável que a abordagem CTS tem esse caráter e pode de maneira muito significativa contribuir na constituição histórica ao Ensino de Ciências da Educação do Campo.

Vale também afirmar que a abordagem CTS tem uma forte conotação contra hegemônica da Ciência neutra, assim como a Educação do Campo. São as contradições entre a lógica do agronegócio e a agroecologia camponesa que estão no cerne da problemática levantada por este trabalho.

\section{Referências}

AIKENHEAD, G. S. Research Into STS Science Education. Revista Brasileira em Educação em Ciências, v. 9, n. 1, p. 1- 21, 2009.

ARAUJO, M. I. O.; CARDOSO, L. R. Entre o exigido e o produzido: o currículo escolar por professores de Ciências em escolas do campo. In: VII ENCONTRO NACIONAL DE PESQUISA EM EDUCAÇÃO EM CIÊNCIAS, 7, 2009, Florianópolis. Anais... Florianópolis: ABRAPEC, 2009, p. 1- 12. 
BRASIL. Diretrizes operacionais para Educação Básica do Campo. Resolução CNE/CEB n. 1. de 03 de abril de 2002. Ministério da Educação - Secretaria de Educação Continuada, Alfabetização e Diversidade - SECAD. Revista.

BRITTO, N. S.; SILVA, R. M. G. Ciências da Natureza e Educação do Campo: caminhos entrelaçados pela trajetória docente. In: I ENCONTRO DE PESQUISAS E PRÁTICAS EM EDUCAÇÃO DO CAMPO DA PARAÍBA, 1., 2011, João Pessoa. Anais... João Pessoa: UFPB, 2011, p. 1-16.

CALDART, R. S. Educação do Campo. In: Caldart et al. Dicionário da Educação do Campo. Rio de Janeiro, São Paulo: Escola Politécnica de Saúde Joaquim Venâncio, Expressão Popular, 2012.

DELIZOICOV, D.; ANGOTTI, J. A.; PERNAMBUCO, M. M. Ensino de Ciências: fundamentos e métodos. 3. ed. São Paulo: Cortez, 2009. 368 p.

FOUREZ, Gerárd. A Construção das Ciências: Introdução à filosofia e à ética das ciências. Trad. Luiz Paulo Rouanet. São Paulo: UNESP, 1995. (Biblioteca básica).

FREIRE, P. Pedagogia do Oprimido. 17. ed. Rio de Janeiro: Paz e Terra. 1987.

KLIEMANN, Claudia Regina Machado. Percepções docentes sobre o ensino de Ciências e a Educação do Campo em escolas do município de Toledo/PR. 2017. 167 f. Dissertação (Mestrado em Educação) - Programa de Pós-Graduação em Educação. Área de concentração: Sociedade, Estado e Educação, Linha de Pesquisa: Ensino de Ciências e Matemática, Universidade Estadual do Oeste do Paraná - UNIOESTE, Cascavel, 2017.

MOLINA, M. C.; SÁ, L. M. M. Escola do Campo. In: Caldart et al. Dicionário da Educação do Campo. Rio de Janeiro, São Paulo: Escola Politécnica de Saúde Joaquim Venâncio, Expressão Popular, 2012.

MOLINA, M. C.; ROCHA, M. I. A.; MARTINS, M. F. A. Dossiê A produção do Conhecimento na Licenciatura em Educação do Campo: desafios e possibilidades para o fortalecimento da Educação do Campo. Revista Brasileira de Educação, v. 24, e240051. 2019. Disponível em: https://www.scielo.br/pdf/rbedu/v24/1809-449X-rbedu-24-e240051.pdf. Acesso em: 01/10/2020.

MORTIMER, E. F. As Chamas e os Cristais Revisitados: estabelecendo diálogos entre a linguagem científica e a linguagem cotidiana no ensino das Ciências da natureza. In: SANTOS; MALDANER (Org.). Ensino de Química em foco. Ijuí: Ed. Unijuí, 2010.

PINTO, A. V. O conceito de tecnologia. Rio de Janeiro: Contraponto, 2005. p. 219-235.

SANTOS, W. L. P. Significados da Educação científica com enfoque CTS. In: SANTOS; AULER (Org.). CTS e educação científica: desafios, tendências e resultados de pesquisas. Brasília: Editora Universidade de Brasília, 2011.

SANTOS, W. L. P.; MORTIMER, E. F. Tomada de decisão para ação social responsável no ensino de ciências. Revista Ciência e Educação, v. 7, n. 1, p. 95-111, 2001. 
SANTOS, W. P. Uma análise de pressupostos teóricos da abordagem CTS no contexto da Educação Brasileira - ensaio. Pesquisa em Educação em Ciências, v. 02, n. 2, dez. 2002.

STRIEDER, R. B. Abordagem CTS e Ensino Médio: Espaços de Articulação. 2008. 236 f. Dissertação (Mestrado em Educação) - Universidade de São Paulo, São Paulo, 2008.

WATANABE, G. Elementos para uma abordagem temática: a questão das águas e sua complexidade. Dissertação (Mestrado em Ensino de Ciências) - Universidade de São Paulo, São Paulo, 2008.

\section{Sobre os autores:}

Maria José Aguiar dos Reis Silva: Mestra em Ensino de Ciências - Programa de Pós Graduação em Ensino de Ciências da Universidade de Brasília - PPGEC/UnB, graduada em Licenciatura em Ensino de Ciências pela Faculdade UnB Planaltina. Atua como Assessora Pedagógica da Coordenação Regional de Educação de Planaltina. Professora da rede pública do Estado de Goiás há 20 anos, com experiência em alfabetização, Ensino Fundamental I e II, Ensino Médio Regular, Educação de Jovens e Adultos - EJA, coordenação pedagógica e gestão escolar.

E-mail: maria.reissilva@seduc.go.gov.br.

Marcelo Ximenes Aguiar Bizerril: Professor Associado da Universidade de Brasília, com Doutorado em Ecologia pela Universidade de Brasília e Pós-doutorado em Políticas do Ensino Superior pela Universidade de Aveiro. Trabalha com formação de educadores desde 1996 nas áreas de biologia, ciências naturais, educação ambiental e educação do campo. Os principais temas de pesquisa e publicações são ensino de ciências, sustentabilidade, educomunicação, gestão do ensino superior, Cerrado e ecologia das interações entre animais e plantas. É membro do Programa de Pós-graduação em Educação em Ciências (UnB).

E-mail: marcelo_bizerril@yahoo.com.br. 